"Here's a question you need to ask everybody running as a Republican: what is the environmental policy of the Republican Party?" Graham said. "When I ask that question, I get a blank stare."

Graham could not be more correct. It has been clear for some time that climate change is a defining social, and therefore political, issue for the twenty-first century. Questions remain about what kind of impacts to expect and how best to reduce greenhouse-gas emissions, while extending the benefits of modern industry to the world's poorest citizens. But the core science is solid, and policy-makers at all levels have a responsibility to engage with it. Sadly, the Republican Party's strategy in Congress thus far has been to ignore or dodge the problem, or to deny it outright.

Fellow candidates such as senators Marco Rubio of Florida and Ted Cruz of Texas have both questioned the science of global warming or humanity's contribution to it, as has former Pennsylvania senator Rick Santorum. When the US Senate took up a pair of symbolic resolutions in January, just 15 Republicans voted in favour of an amendment declaring that human activity contributes to climate change, and only 5 were willing to support a resolution stating that the human contribution is significant.

So far, the only significant Republican engagement on climate has come in the form of opposition to regulations being imposed by the administration of President Barack Obama. Those regulations are in place for cars and trucks, and the administration is expected to finalize a rule to limit carbon pollution by the electricity sector as early as next month. Just last week, the Environmental Protection Agency released a draft "endangerment" finding that will enable the agency to regulate emissions from aeroplanes, in accordance with standards being negotiated through the International Civil Aviation Organization.

Many on the right - including Senator Graham - have argued against these regulatory efforts, and there are legitimate reasons for doing

so. Most experts agree that it would be much more effective to tackle the issue in a comprehensive way, whether through a market-based regulatory emissions scheme like that adopted in the European Union, or a simple carbon tax. An insurgent environmental faction in the Republican Party is pushing for the latter, perhaps paired with a dividend system that would make the tax revenue-neutral and offset the higher prices paid by consumers for petrol and for fossil-fuel-based electricity, as a sim-

"The rest of the world has moved beyond questions about whether climate change is real." pler conservative solution. But before they can even think about laying out a proactive agenda, Republicans must acknowledge the problem.

In this sense, Senator Graham's challenge is a step forward. Not only is it in line with mainstream science, but it also chimes with mainstream views within the US public. A March survey by the Yale Project on Climate Change Communication found that $63 \%$ of Americans believe that global warming is happening and $52 \%$ think that it is mostly caused by humans; just $18 \%$ think that it is not happening, with $32 \%$ believing that it is mostly due to natural environmental factors. Also, $71 \%$ of Americans "mostly" or "somewhat" trust climate scientists, compared with $27 \%$ who mostly or somewhat distrust them. Even the corporate community that Republicans claim to represent is beginning to engage with climate change. And Pope Francis has issued his own call to action on climate change this week (see go.nature.com/19lurz).

The rest of the world has moved beyond questions about whether climate change is real and is focused on how best to address it. There is plenty of pressure on Republicans to do the same, but the challenge to party orthodoxy ultimately needs to come from within. Senator Graham has put the problem on the Republican presidential agenda. To build momentum, he and other brave souls will now need to start talking about solutions.

\section{Risky business}

\section{Funding agencies should highlight their roles as risk managers to underpin public trust.}

$\mathrm{A}$ nyone who has helped to run an organization knows that good governance includes regular evaluation of risks - risks to employees, to security, to processes, to reputation, to financial viability - and, where these risks are considered excessive, actions to mitigate them. Risk assessments of this type need to be specific, so inevitably they are confidential.

Research funders who steward the allocation of millions or billions of dollars routinely assess and manage such risks. But they also deal with other kinds of risk - and success in those areas should not be kept quiet.

There are two types of risk management that funders should highlight: one that deals with bad risk, and the other with good.

The bad risks involve funds being wasted on inept, sloppy or downright fraudulent research. Funding agencies are usually responsible to taxpayers; it is therefore crucial that they are publicly accountable for ensuring that they support robust science. This is easily said. How can it be done? The least that the funder can do is to ensure that the institutions that it funds have procedures for tackling sloppy or dishonest research when it arises and, better still, for reducing the likelihood of such problems through appropriate scrutiny and training.

Journals tackling the challenges of reproducibility have found that measures to ensure that research is robust can be onerous for editors, referees and authors. The same will be true for funders. But if public trust in science is to be maintained, funders need to mitigate bad risks through assessment procedures. They could, for example, ensure that claims about the statistical power of proposed experiments stand up. What is more, they need to be seen to be doing this.

One funder that has taken these responsibilities seriously is the US National Institutes of Health. To tackle poor reproducibility in biomedical research, it has arranged discussion meetings, introduced training programmes and made its assessment of grant applications more rigorous. It has also made these initiatives highly visible: see go.nature.com/8jhvwq. Others should follow its example.

Then there are the good risks. At a meeting of the Global Research Council in Tokyo last month, funders produced a declaration of principles to address the challenges of funding scientific breakthroughs (see go.nature.com/nrlxmd). The most consistent point was that funders should feel able to take positive risks - that is, to support daring ideas that have a chance of failure. They should "encourage risk-taking and tolerate failure in research activities". And they should "provide researchers with the flexibility and intellectual space needed for serendipity". Much of this comes down to funders ensuring "the freedom of researchers in defining their topics, their methodologies and their resource allocations".

Although such boldness is not easy to implement, researchers know what the combination of great talent and bold ideas can deliver. Outsiders, including governments and taxpayers, might not appreciate the potential value of positive risk-taking. But it goes with the territory of supporting outstanding science.

It is important, therefore, that funding-agency managers empower selection committees to accept a degree of risk in supporting boldness $\rightarrow$ NATURE.COM To comment online, click on Editorials at: go.nature.com/xhunqv in research, and to back researchers up when (and it will be when, not if) some of those risks do not pay off. Any funding agency that lives up to these principles should proclaim its risktaking mission with pride. 